\title{
Expression analysis of plectin isoforms in osteoclast
}

\author{
Takuma Matsubara $^{1 *}$, Mariko Urata ${ }^{1}$, William N Addison ${ }^{2}$ and Shoichiro Kokabu ${ }^{1}$ \\ ${ }^{1}$ Division of Molecular Signaling and Biochemistry, Kyushu Dental University, 2-6-1, Manazuru, Kitakyushu, Fukuoka, 8038580, Japan \\ ${ }^{2}$ Research Unit, Shriners Hospitals for Children-Canada, Department of Human Genetics, McGill University, Montreal, Quebec, Canada
}

\begin{abstract}
Bone homeostasis is maintained by osteoclasts and osteoblasts. Regulation of bone homeostasis is important for orthodontic treatments, oral implant, treatment for periodontal disease, osteonecrosis of the jaw and so on. We reported an intermediate filament linking protein Plectin plays important role in osteoclastic bone resorption. Plectin is a large molecule $>500 \mathrm{kDa}$ and have 13 isoforms. Individual Plectin isoforms have different roles. To reveal the roles of Plectin in osteoclasts, we examined the expression levels of Plectin isoforms and found the isoforms regulating actin organization are highly expressed in osteoclasts.
\end{abstract}

\section{Introduction}

Osteoclasts are one of the major player for bone resorption and regulate bone remodeling to maintain bone homeostasis [1,2] Activation of osteoclastic bone resorption in comparison with bone formation by osteoblasts results in bone metabolic diseases such as osteoporosis and periodontal disease [3-5]. Moreover, the function of osteoclasts is important in orthodontic treatments, oral implant treatment and pathogenesis of osteonecrosis of the jaw [6-9]. Thus, regulation of osteoclasts is one of the serious themes for improvement of various dental treatments.

Osteoclasts are differentiated from hematopoietic stem cells with macrophage colony stimulating factor (M-CSF) and Receptor activator NF- $\mathrm{KB}$ ligand (RANKL) stimulation [1,2]. Attachment and sealing of bone matrix by differentiated osteoclasts is essential for bone resorption $[10,11]$. Actin, tubulin and intermediate filaments are dynamically organized and forms actin ring that is consistent with actin dots called podosomes in cell periphery for attachment and sealing [12-15]. It is well known that the mice defect actin ring formation by knocking out a tyrosine kinase Src are osteopetrosis because of decrease of bone resorbing activity $[16,17]$. This indicates Src is one of the key molecules to regulate bone resorption.

We identified a cytolinker protein Plectin as a partner of Src and organize actin ring formation in osteoclasts [13]. Plectin was highly expressed in brain, heart, skeletal muscle and TRAP(+) MNCs $[13,14,18,19]$. Plectin has 13 isoforms and there role is a little different each other [18]. This suggests Plectin variants plays different roles in each tissue. Here, we explore the important isoforms of Plectin in osteoclasts.

\section{Materials and methods}

\section{Animals}

4 weeks old C57BL6/N mice were purchased from Japan SLC, Inc. (Shizuoka, Japan). Spleen and femoral muscle were obtained from these mice. Spleen cells were differentiated to osteoclast like cells with M-CSF and sRANKL described as previously $[13,15]$. Femoral muscle was mashed with Biomasher II purchased from Nippi (Tokyo, Japan) and obtained mRNA described below.

\section{Real-time quantitative PCR}

Total RNA of the biceps muscle of the thigh, spleen cell derived osteoclasts as described previously [15]. rRNAs were isolated with FastGene $^{\mathrm{m}}$ RNA Basic Kit from Nippon genetics Co., ltd. (Tokyo, Japan). cDNA was synthesized from $1 \mu \mathrm{g}$ of total RNA by using ReverTra Ace from TOYOBO (Tokyo, Japan). Real-time quantitative PCR was performed by incubating cDNA, PowerUp SYBR ${ }^{\mathrm{m \omega}}$ Green Master Mix from Thermo Fisher Scientific and primers indicated at below in a QuantStudio 3 Real-time PCR system purchased from Thermo Fisher Scientific (San Jose, CA). All reactions were performed in triplicate and analyzed. The expression level was normalized by Gapdh expression.

The primer sequences were: Gapdh, 5'-aactttggcattgtggaagg- $3^{\prime}$ (forward) and 5'-acacattggggtaggaaca-3' (reverse); Plec1, 5'-ggagcctgccccagccacag- $3^{\prime}$ (forward); Plec1a, 5'-gggcaagaaagatgaacgag- $3^{\prime}$ (forward); Plec1b , 5' - cggcaggcaaaggatgagcaag-3' (forward); Plec1c, 5' - ggccgtcatccgcattgcag-3' (forward); Plec1d, 5'- ccccaatgaagatcgtgcccg- $3^{\prime}$ (forward); Plec1e, 5' - agcacgagatcagctccctcaaag-3' (forward); Plec1f, 5' aggaggtgcgggagaagtacaaag- $3^{\prime}$ (forward); Plec1g, 5' - ctctacgggcaactctgttgtgtag-3' (forward); Plec1hij, 5'- atgaacgagaccgtgtgcagaag-3' (forward); Plec1 common, 5' - cctgagaggacttccagcag- $3^{\prime}$ (reverse); Src, 5'- gttgcttcggagaggtgtggat-3' (forward) and 5'- caccagtttctcgtgcctcagt- $3^{\prime}$ (reverse). The experiments were individually performed at least twice and obtained representative data.

\section{Data analysis and statistics}

The experiments were performed at least twice. Differences between groups were analyzed by the Student's t-test to determine statistical significance. A value of $\mathrm{P}<0.01$ was considered statistically significant.

${ }^{*}$ Correspondence to: Takuma Matsubara, Division of Molecular Signaling and Biochemistry, Department of Health Improvement, Kyushu Dental University, 2-6-1, Manazuru, Kitakyushu, Fukuoka, 8038580, Japan, Tel: +81-93-285-3049, Fax: +81-93-582-6000, E-mail: r15matsubara@fa.kyu-dent.ac.jp

Received: February 01, 2019; Accepted: February 15, 2019; Published: February 18,2019 

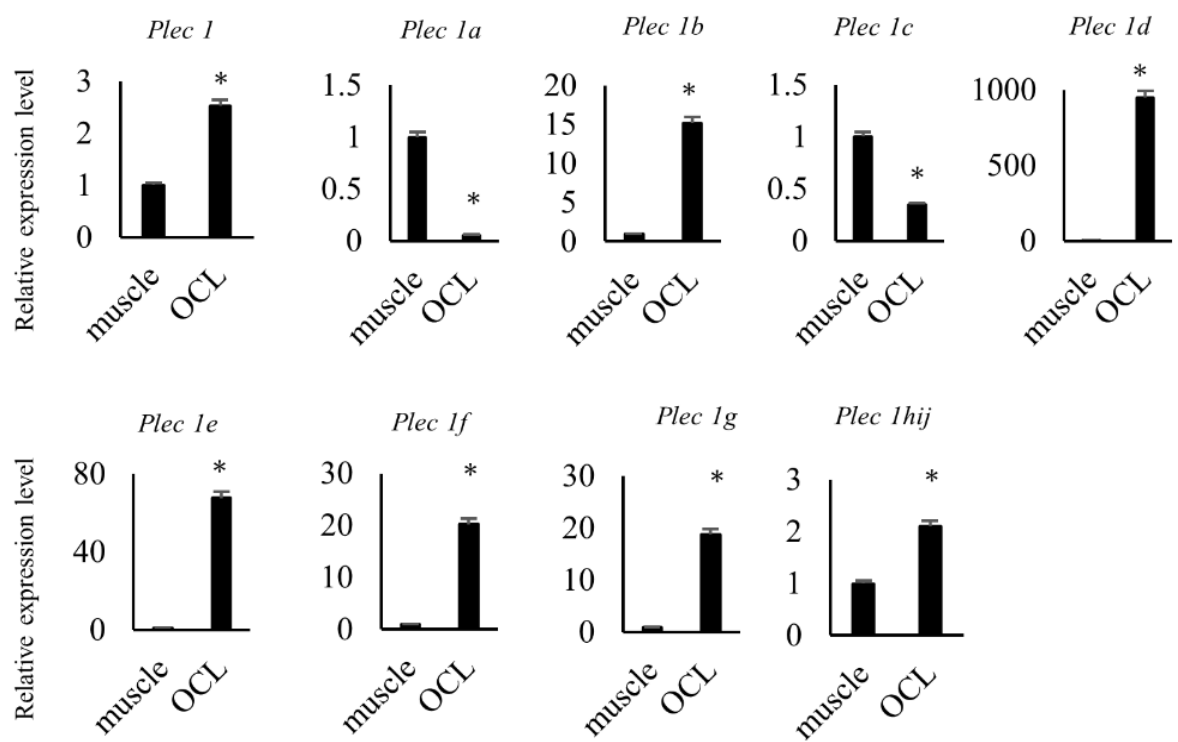

Figure 1. High expression level of Plectin mRNA in osteoclast like cells

mRNA was harvested from femur muscle (described as muscle) and osteoclast like cells (described as OCL) derived from spleen cells stimulated with $30 \mathrm{ng} / \mathrm{mL}$ of M-CSF and $100 \mathrm{ng} / \mathrm{mL}$ of sRANKL for 7days. Expression level of Plectin isoforms' mRNA was measured by quantitative RT-PCR

\section{Results}

To explore what isoform is expressed in osteoclasts, we performed real-time quantitative PCR analysis compared with skeletal muscle where what isoform is working [20] (Figure 1). Expression level of Plectin $1,1 \mathrm{~b}, 1 \mathrm{~d}, 1 \mathrm{e}, 1 \mathrm{f}$ and $1 \mathrm{~g}$ in TRAP(+) MNCs was higher than in skeletal muscle (Figure 1). Plectin $1 \mathrm{~h}, 1 \mathrm{i}$ and $1 \mathrm{j}$ were not distinguished each other due to primer design. On the other hand, Plectin 1a and $1 \mathrm{c}$ were less in TRAP (+) MNCs.

\section{Discussion}

Plectin is a large protein which is involving various intracellular signaling such as actin organization, microtubule organization, IF organization and so on [18]. Plectin has 13 transcriptional variants in its amino terminal domain. These variants may control Plectin localization and part of binding proteins. Plectin is expressed in various tissues such as brain, heart, skeletal muscle and TRAP (+) MNCs [13]. The detected molecular weight of Plectin was different by tissues. This suggests Plectin variants plays different roles in each tissue. Plectin $1,1 \mathrm{~b}, 1 \mathrm{~d}, 1 \mathrm{e}, 1 \mathrm{f}$, and $1 \mathrm{~g}$ were higher expressed in osteoclasts than in skeletal muscle in this study. Plectin $1,1 \mathrm{~d} 1 \mathrm{e}, 1 \mathrm{f}$ and $1 \mathrm{~g}$ were localized in podosomes, and 1e and if were localized in focal adhesion of SW 480 colon carcinoma cells [21]. These results suggest that the Plectin variants that needs for actin ring formation and attachment to bone matrix is highly expressed in osteoclasts. Further investigation for individual Plectin isoform analysis needs for understanding the mechanisms of osteoclastic bone resorption.

\section{Conclusion}

Plectin $1,1 \mathrm{~b}, 1 \mathrm{~d}, 1 \mathrm{e}, 1 \mathrm{f}$, and $1 \mathrm{~g}$ were higher expressed in osteoclasts and may play important role in osteoclastic bone resorption.

\section{Author's contributions}

T.M. designed this study and performed most of the experiments. M.U. performed mRNA isolation from osteoclasts. S.K. helped with qPCR data analysis. W.A. performed literature review.

\section{Conflicts of interest}

All authors state that they have no conflicts of interest.

\section{Acknowledgements}

This work was supported by grants from the Ministry of Education, Culture, Sports, Science and Technology of Japan (KAKENHI 25670870 and 18K09509 to T.M.).

\section{References}

1. Takahashi N, Ejiri S, Yanagisawa S, Ozawa H (2007) Regulation of osteoclast polarization. Odontology 95: 1-9. [Crossref]

2. Takayanagi H (2007) Osteoimmunology: Shared mechanisms and crosstalk between the immune and bone systems. Nat Rev Immunol 7: 292-304. [Crossref]

3. Bruzzaniti A, Baron R (2007) Molecular regulation of osteoclast activity. Rev Endocr Metab Disord 7: 123-139. [Crossref]

4. Horne WC, Sanjay A, Bruzzaniti A, Baron R (2005) The role(s) of Src kinase and Cbl proteins in the regulation of osteoclast differentiation and function. Immunol Rev 208 106-125. [Crossref]

5. Fan J, Caton JG (2018) Occlusal trauma and excessive occlusal forces: Narrative review, case definitions, and diagnostic considerations. J Periodontol 89: S214-S222. [Crossref]

6. Kitaura H, Kimura K, Ishida M, Sugisawa H, Kohara H, et al. (2014) Effect of cytokines on osteoclast formation and bone resorption during mechanical force loading of the periodontal membrane. ScientificWorldJournal 2014: 617032. [Crossref]

7. Yamaguchi M (2009) RANK/RANKL/OPG during orthodontic tooth movement. Orthod Craniofac Res 12: 113-119. [Crossref]

8. Kanzaki H, Chiba M, Shimizu Y, Mitani H (2002) Periodontal ligament cells under mechanical stress induce osteoclastogenesis by receptor activator of nuclear factor kappaB ligand up-regulation via prostaglandin E2 synthesis. J Bone Miner Res 17: 210-220. [Crossref]

9. Allen MR, Burr DB (2009) The pathogenesis of bisphosphonate-related osteonecrosis of the jaw: so many hypotheses, so few data. J Oral Maxillofac Surg 67: 61-70. [Crossref]

10. Destaing O, Sanjay A, Itzstein C, Horne WC, Toomre D, et al. (2008) The tyrosine kinase activity of c-Src regulates actin dynamics and organization of podosomes in osteoclasts. Mol Biol Cell 19: 394-404. [Crossref]

11. Gil-Henn H, Destaing O, Sims NA, Aoki K, Alles N, et al. (2007) Defective microtubule-dependent podosome organization in osteoclasts leads to increased bone density in Pyk2(-/-) mice. J Cell Biol 178: 1053-1064. [Crossref] 
12. Jurdic P, Saltel F, Chabadel A, Destaing O (2006) Podosome and sealing zone: Specificity of the osteoclast model. Eur J Cell Biol 85: 195-202. [Crossref]

13. Matsubara T, Kinbara M, Maeda T, Yoshizawa M, Kokabu S, et al. (2017) Regulation of osteoclast differentiation and actin ring formation by the cytolinker protein plectin. Biochem Biophys Res Commun 489: 472-476. [Crossref]

14. Matsubara T, Kinbara M, Maeda T, Yoshizawa M, Kokabu S, et al. (2018) Plectin , A Cytolinker Protein, Plays an Important Role in Differentiation and Actin Ring Formation in Osteoclasts. Mathews J Cytol Histol 1: 6-8.

15. Matsubara T, Kokabu S, Nakatomi C, Kinbara M, Maeda T, et al. (2017) The actinbinding protein PPP1r18 regulates maturation, actin organization, and bone resorption activity of osteoclasts. Mol Cell Biol 38: e00425-17. [Crossref]

16. Soriano P, Montgomery C, Geske R, Bradley A (1991) Targeted disruption of the c-src proto-oncogene leads to osteopetrosis in mice. Cell 64: 693-702. [Crossref]
17. Boyce BF, Yoneda T, Lowe C, Soriano P, Mundy GR (1992) Requirement of pp60c-src expression for osteoclasts to form ruffled borders and resorb bone in mice. $J$ Clin Invest 90: 1622-1627. [Crossref]

18. Castañón MJ, Walko G, Winter L, Wiche G (2013) Plectin-intermediate filament partnership in skin, skeletal muscle, and peripheral nerve. Histochem Cell Biol 140: 33-53. [Crossref]

19. Wiche G, Winter L (2011) Plectin isoforms as organizers of intermediate filament cytoarchitecture, Bioarchitecture 1: 14-20. [Crossref]

20. Konieczny P, Fuchs P, Reipert S, Kunz WS, Zeöld A, et al. (2008) Myofiber integrity depends on desmin network targeting to Z-disks and costameres via distinct plectin isoforms. J Cell Biol 181: 667-681. [Crossref]

21. McInroy L, Määttä A (2011) Plectin regulates invasiveness of SW480 colon carcinom cells and is targeted to podosome-like adhesions in an isoform-specific manner. Exp Cell Res 317: 2468-2478.

Copyright: (C2019 Matsubara T. This is an open-access article distributed under the terms of the Creative Commons Attribution License, which permits unrestricted use, distribution, and reproduction in any medium, provided the original author and source are credited. 